\title{
Medical equipment bio-capability processes using the atmospheric plasma-sprayed titanium coating
}

\author{
F. Rezaei ${ }^{1} \cdot$ S. Saviz ${ }^{1} \cdot$ M. Ghoranneviss ${ }^{1}$
}

Received: 15 March 2017 / Accepted: 4 November 2017 / Published online: 26 December 2017

(C) The Author(s) 2017. This article is an open access publication

\begin{abstract}
Antibacterial surfaces such as titanium coatings are able to have capability in the human body environment. In this study, titanium coatings are deposited on the 316 stainless steel substrates by a handmade plasma spray system. Some mechanical, chemical properties and microstructure of the created titanium layer are determined to evaluate the quality of coating. The XRD, SEM, adhesion tests from cross cut and corrosion test by potentiodynamic are used. During the different stages, some of the parameters are changed in different samples to achieve the best quality in the coating. It is shown that by increasing the spray time, the production of nanoparticles begins. On the other hand, the best layers are created when the spray main gas flow rate has a certain amount.
\end{abstract}

Keywords Plasma Spray · Bio-capability · Titanium

\section{Introduction}

Due to extensive properties of titanium (Ti) such as high resistance to corrosion, low conductivity, nontoxicity and bio compatibility, its use in medicine and industry has increased. Suleiman et al. [1] investigated the plasma spray deposition parameters to evaluate the mechanical and microstructural properties of the nano size $\left(\mathrm{TiO}_{2}\right)$ particle on the coating. Feng et al. [2] generated $\left(\mathrm{TiO}_{2}\right)$ powder in nano size with plasma spray technique. Ong et al. [3] evaluated the plasma-sprayed hydroxyapatite (HA) and titanium plasma-sprayed (TPS) implants inside the body condition. They showed that implants that were prepared with plasma spray technique illustrate similar pull-out strength compared to the HA implants. Ref. [4] present the semiconducting properties of anodic oxide films on the titanium. They use potentiostatic anodization technique in PBS and ringer solutions. Goudarzi et al. show that the antibacterial surfaces such as copper coatings are able to reduce the growth of bacteria [5]. According to the high cost of using titanium, they tried to create the deposited

S. Saviz

shahrooz.saviz@srbiau.ac.ir

$1 \quad$ Plasma Physics Research Center, Science and Research Branch, Islamic Azad University, Tehran, Iran titanium on the stainless steel substrate and affordable the titanium favorable properties.

Despite the different coating methods, because of its many benefits such as high melting point, resistance to corrosion and abrasion, plasma spray is chosen [6-10].

In this paper, titanium powder is coated on sandblasted stainless steel substrate by atmospheric plasma spray. Generally in this arrangement and device some parameters such as voltage and current, type and rate of carrier gas and torch gas, powder rate and spray distance could be changed. The main novelty of our manuscript is the investigation of the plasma spray parameters on the bio-capability of the $\left(\mathrm{TiO}_{2}\right)$ coatings. In "Materials and methods" section the materials and methods are explained. The little summary about the analysis is given in "Analysis" section. The results and discussion are shown in "Result and discussion" section and some important results are given in "Conclusions" section.

\section{Materials and methods}

The feed stock powder is the titanium powder in the particle size range from 30 to $63 \mu \mathrm{m}$. We use the home-made atmospheric plasma spraying system that is located in plasma physics research center. The schematic of the spray 
Fig. 1 The sketch map of plasma spray system (a) plasma spray under operation (b), the schematic of the plasma torch system (c)
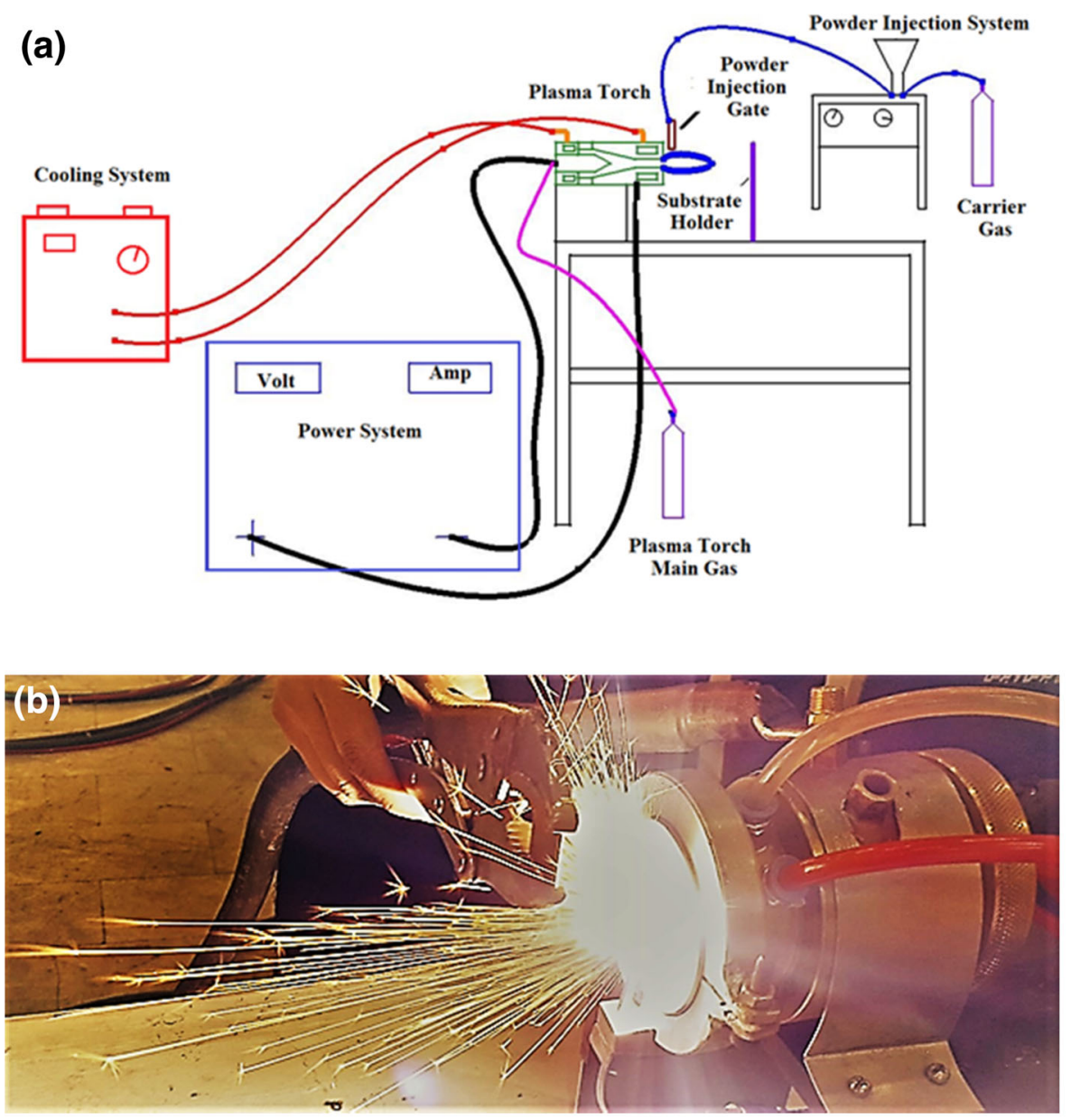

(c)

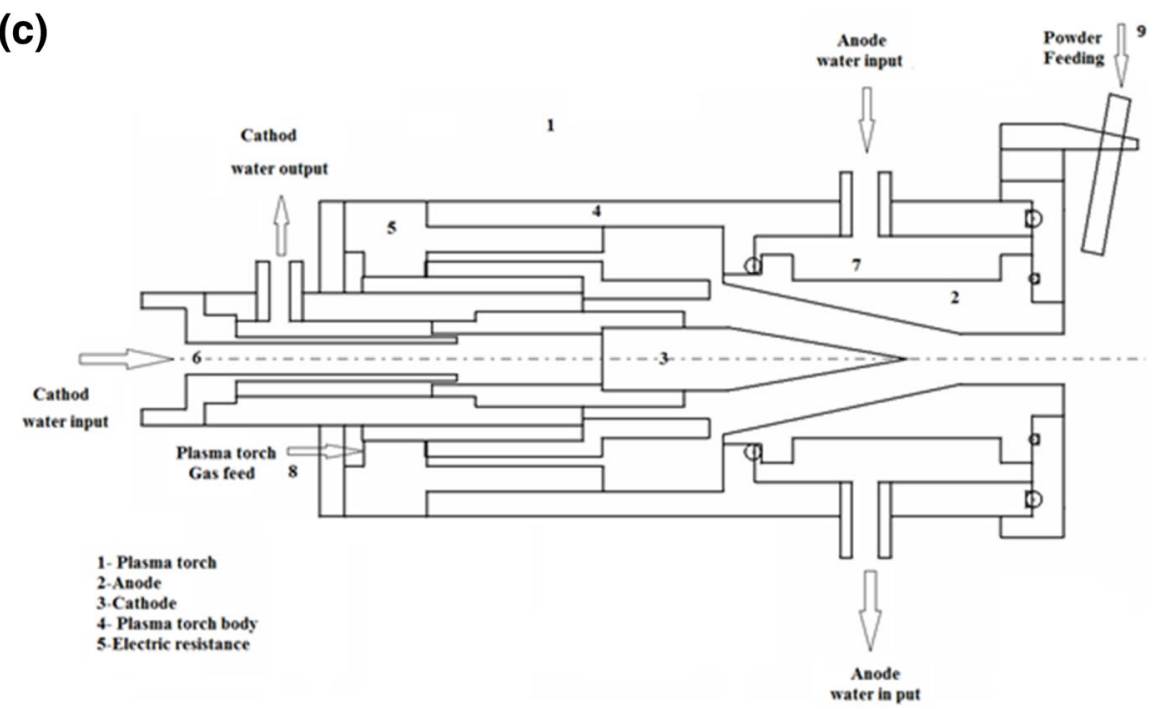

system and our plasma spray under operation are shown in Fig. 1a-c, respectively. The titanium powder is deposited with atmospheric plasma spraying system (APS) (power $20 \mathrm{~kW}$, ability to create a temperature in the range $3000^{\circ}$ to $6000{ }^{\circ} \mathrm{K}$, the operating voltage $40 \mathrm{~V}$ and current up to $600 \mathrm{~A}$ is adjustable).
The main ingredients of plasma torch are electrodes, ceramic insulation (to create an electric insulation between cathode and anode), power supply system, powder feeder and the cooling system of anode and cathode.

Spraying distance is selected in the range of $12-17 \mathrm{~cm}$. 
Table 1 The parameter chart

\begin{tabular}{llllllllll}
\hline $\begin{array}{l}\text { Sample } \\
\text { gas }\end{array}$ & $\begin{array}{l}\text { Main } \\
\text { gas }\end{array}$ & $\begin{array}{l}\text { Main gas rate }(\mathrm{l} / \\
\mathrm{min})\end{array}$ & $\begin{array}{l}\text { Carrier gas } \\
\text { rate }\end{array}$ & $\begin{array}{l}\text { Powder rate }(\mathrm{g} / \\
\mathrm{min})\end{array}$ & $\begin{array}{l}\text { Spray distance } \\
(\mathrm{cm})\end{array}$ & $\begin{array}{l}\text { Voltage } \\
(\mathrm{V})\end{array}$ & $\begin{array}{l}\text { Current } \\
(\mathrm{A})\end{array}$ & $\begin{array}{l}\text { Time of } \\
\text { treatment }(\mathrm{s})\end{array}$ \\
\hline 1 & $\mathrm{Ar}$ & $\mathrm{Ar}$ & 20 & 10 & 3 & 12 & 22 & 590 & 10 \\
2 & $\mathrm{Ar}$ & $\mathrm{Ar}$ & 30 & 10 & 3 & 12 & 22 & 590 & 10 \\
3 & $\mathrm{Ar}$ & - & 20 & - & 3 & 12 & 22 & 590 & 10 \\
4 & $\mathrm{Ar}$ & - & 20 & - & 3 & 17 & 31 & 480 & 15 \\
\hline
\end{tabular}

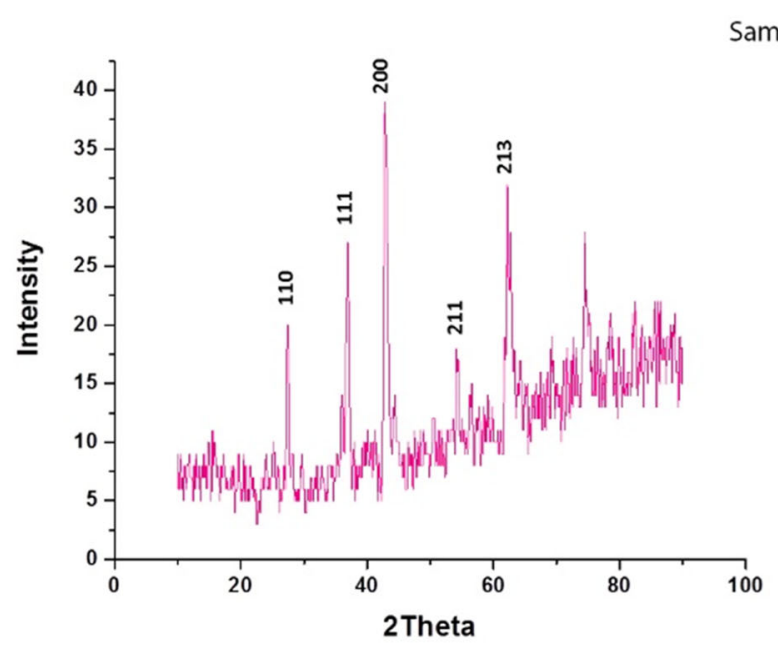

Sample 1

Sample 2
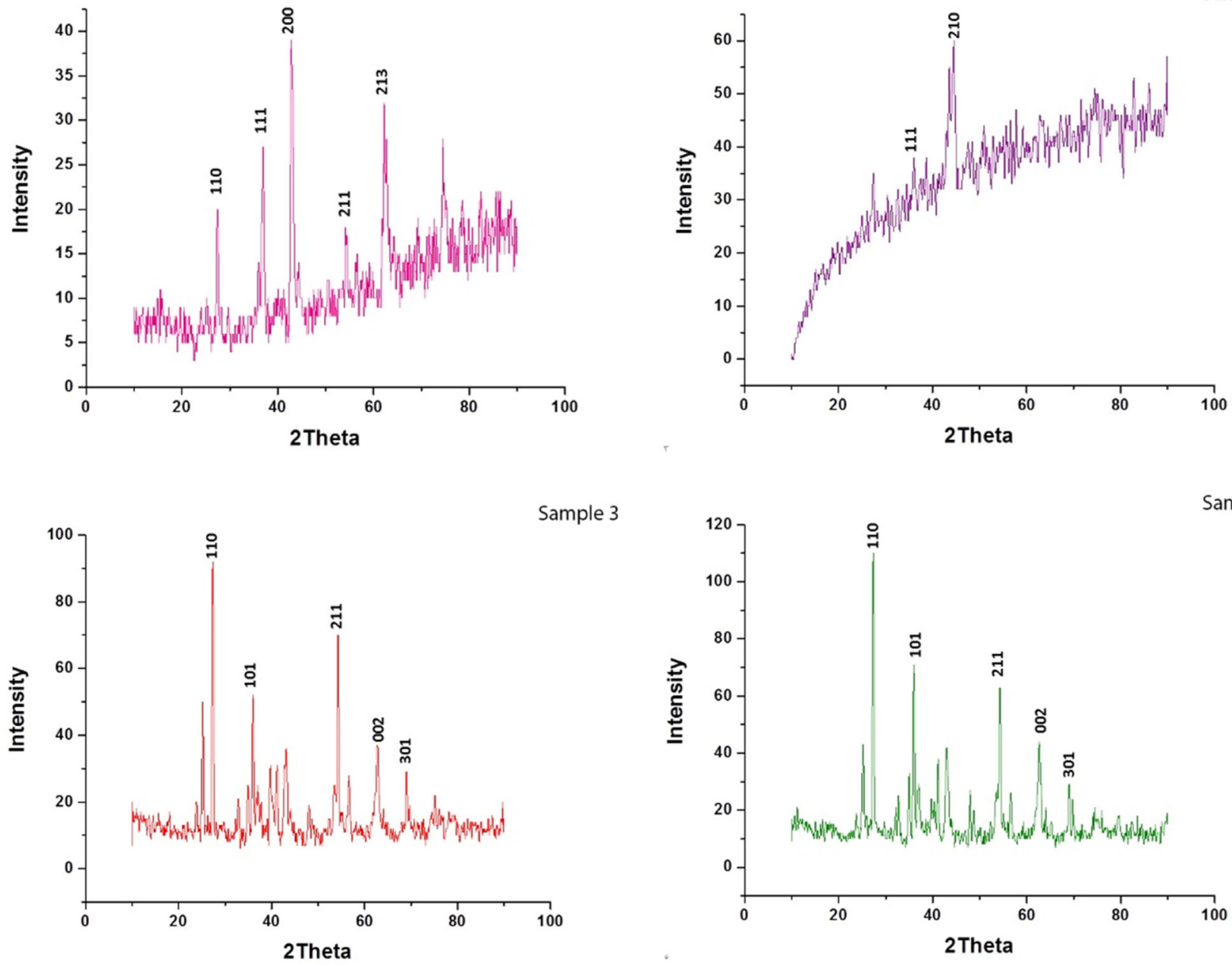

Sample 3

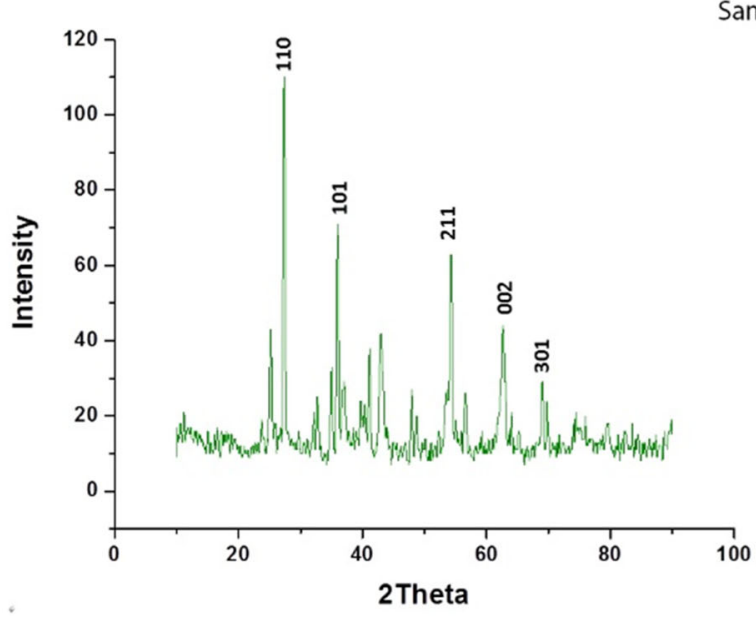

Fig. 2 The XRD pattern of deposited coating on substrate on different samples

Argon is used as powder carrier gas and plasma torch gas.

Powder injection rate is constant ( $3 \mathrm{~g} / \mathrm{min})$.

In this paper the analyses are performed on the four samples with the detailed conditions as illustrated in Table 1.

\section{Analysis}

The coating composition on the substrate is determined by $\mathrm{XRD}$ analysis. The data are collected in the range of $10^{\circ}-$ $90^{\circ}(2 \Theta)$, and the resulting peaks are identified with the miller index [1]. 

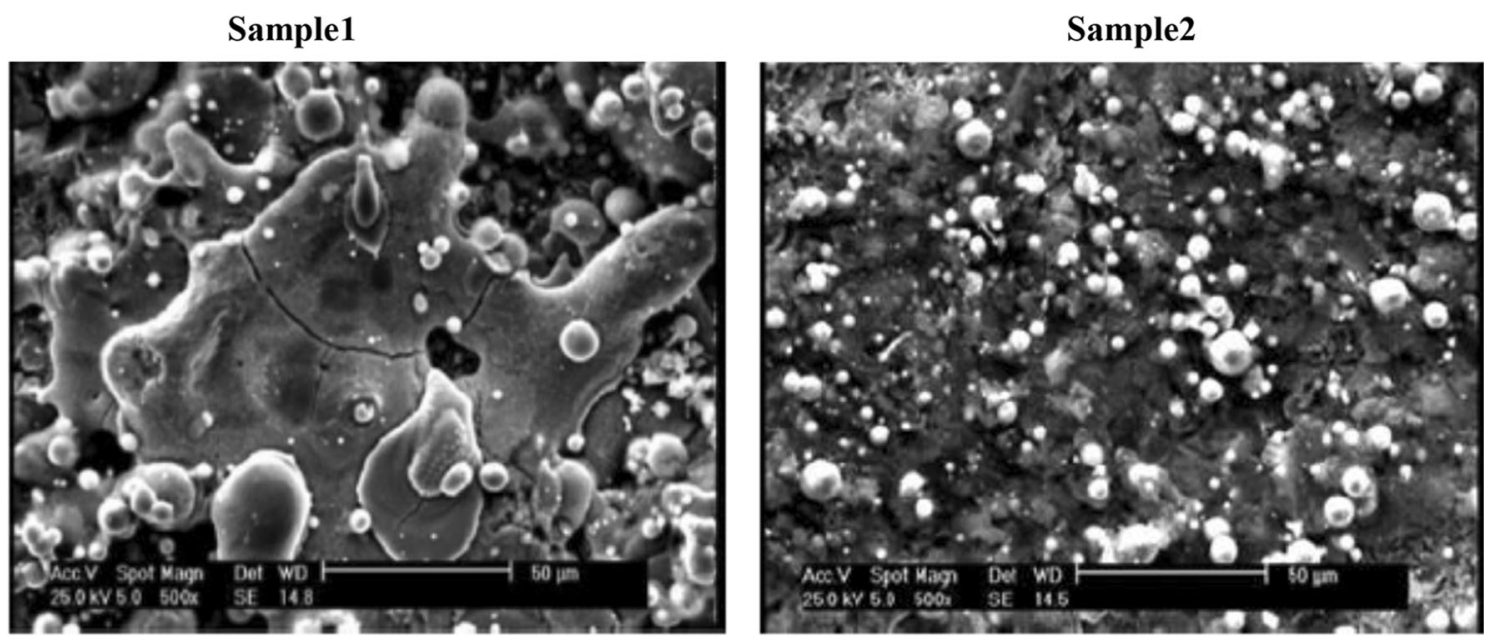

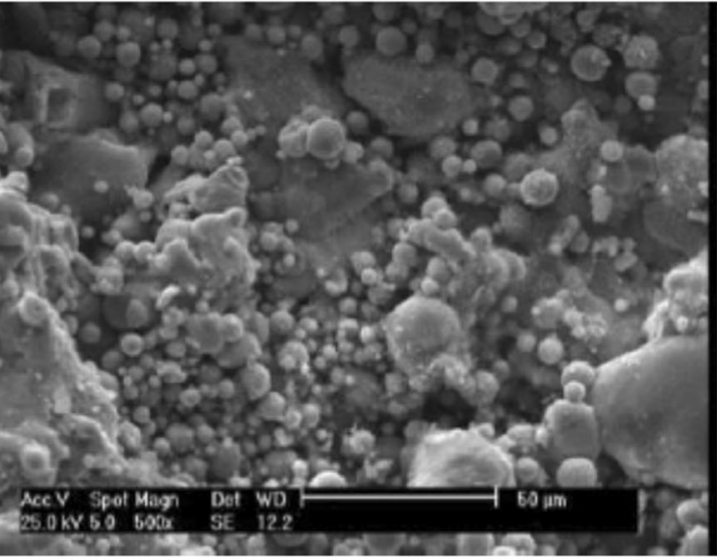

Sample 3

Fig. 3 The SEM micrograph of surface

The morphology and porosity of the deposited layer are examined by SEM. Prior to this test, the samples are coated with gold by the sputter coater (the surface is detected by SE detector) [1].

The corrosion analysis is used to determine the chemical adhesion, the corrosion resistance in saline solution and the bio-compatibility in the physiological environment of the coating. The samples preparations in this test include the insulation of the back and edges to prevent the corrosion reaction from entrance of stainless steel particles [4].

Polarization technique is potentiodynamic, and saline solutions are Ringer and PBS (phosphate-buffered saline) [4]. Finally, the mechanical adhesion of coating is examined by cross cut test (TQC CROSS CUT ADHESION TEST, Netherlands, according to the standard ASTM D3359-09).

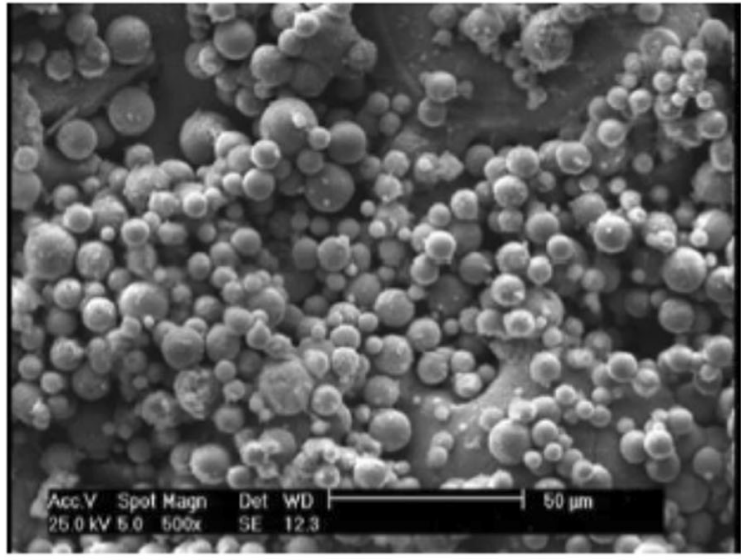

Sample 4

\section{Results and discussion}

\section{XRD analysis}

Figure 2 shows the XRD analysis of samples. The peaks are marked by Miller indexes. As apparent in this figure, comparing the Miller indexes with PDF card (reference code: 00-034-0180) indicates the presence of $\left(\mathrm{TiO}_{2}\right)$ in the coated layers. So $\left(\mathrm{TiO}_{2}\right)$ compounds are provided on substrate by spraying titanium powder. In the second sample limited sharp peaks are observed that indicate the lack of appropriate coating. In other sample more sharp peaks are observed.

\section{The SEM analysis}

Coating microstructure is observed by SEM (Fig. 3). For all samples accelerating voltage $(\mathrm{ACC}=25 \mathrm{kV})$, diameter 


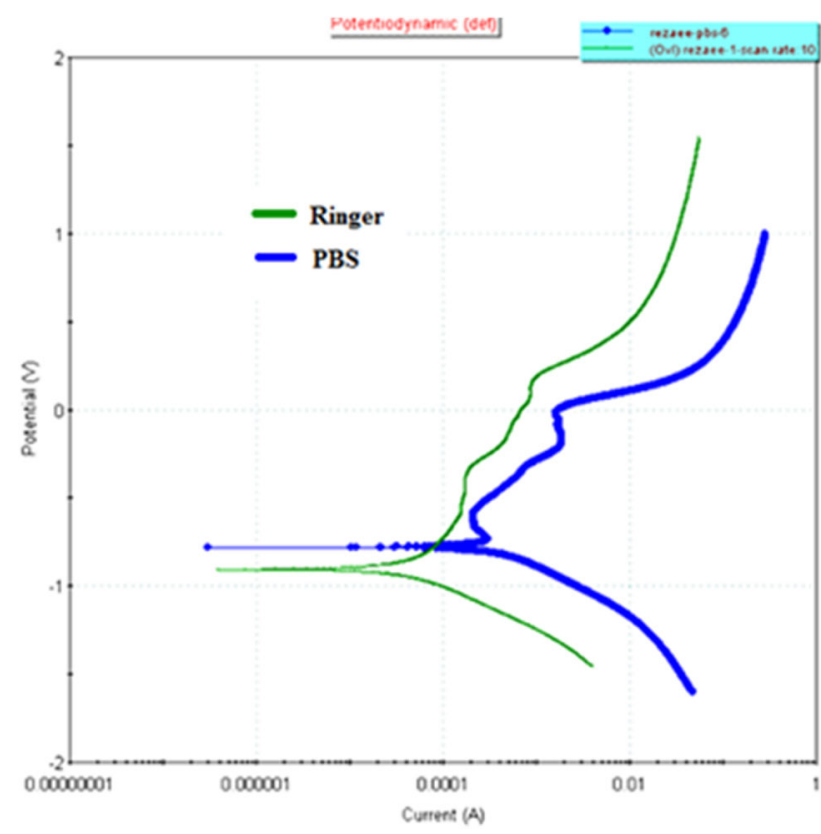

Fig. 4 The potentiodynamic polarization of coating after 6-min immersion in the physiology solution

of electron beam $($ Spot $=5), \quad$ magnification $($ Magn $=\times 500)$, working distance $(\mathrm{WD}=[12.2,14.8])$, scale bar $=50 \mu \mathrm{m}$ and Det $=\mathrm{SE}$ are constant. As seen in Fig. 3, in the first sample in the central part of sample, dense and continuous coating is observed but the density and continuity are reduced around. The measured thickness is $61 \mu \mathrm{m}$.

In the second sample, by increasing the gas rate of torch from 10 to $301 / \mathrm{min}$, the density and continuity of the coated layer are decreased. Due to excessive gas rate, plasma plume is divergent and by increasing the speed of particles, they have not enough the time to completely melt, so semi-molten particles or particles with large size collide with substrate and cause the discontinuity and lowdensity layers. The measured thickness is $49 \mu \mathrm{m}$.

In the third sample to achieve the ideal coating, the rate of torch gas is reduced, as well as the carrier gas, which leads to reduction in deviation from target (fixed distance). In this case, continuous density in the center and edges is observed. In some areas, in addition to creating a uniform layer the discontinuous layer is created on the pervious coated layers. (Due to the scale bar, the particle size is dropped to nano scale). The measured thickness is $58 \mu \mathrm{m}$.

In the fourth sample, the spraying time and distance are changed while other parameters are constant. In this case the coated layer is uniform and the particles size is nano. It can be noted that the spray distance can be increased by increasing the spray time, to reach the desired result of the coating at the better spray distance. The measured thickness is $53 \mu \mathrm{m}$.

\section{Corrosion test}

Corrosion test is used to check the chemical adhesion and corrosion resistance of coating in saline environments (the corrosion resistance in saline environments is proportional with the metal's bio compatibility) [4, 9].

After preparation of the samples, first and third sample, respectively, in Ringer and PBS solution, are placed, for 6 min to balance (Fig. 4). (The effective section area of sample in Ringer solution: $12.2 \times 1.63 \mathrm{~cm}^{2}$, For sample in PBS solution: $1.2 \times 1.7 \mathrm{~cm}^{2}$ ). (scan rate: $10 \mathrm{mv} / \mathrm{s}$, scanning range: $(-1,+1.5)$ to the OCP point) [4].

The corrosion rates of the sample in the Ringer solution ARE less than PBS solution (Table 2). Compared to standard, (ASTM F2129) represents the low corrosion rate at Ringer and average corrosion rates at PBS solution. So with high corrosion resistance at the physiology environment, bio compatibility of the coating can be found [11].
Table 2 Current density and corrosion

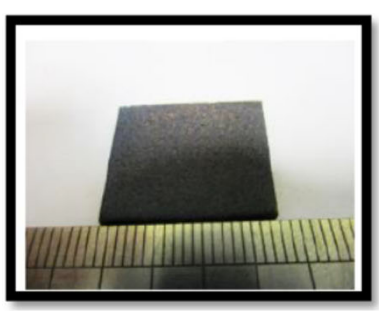

Sample before test run

\begin{tabular}{llc}
\hline & Corrosion current density $\left(i_{\text {corr }}\right)\left(\mu \mathrm{A} / \mathrm{cm}^{2}\right)$ & Corrosion rate $(\mathrm{CR})(\mathrm{mm} /$ year $)$ \\
\hline Ringer solution & $2.55 \times 10$ & 4.2 \\
PBS solution & $3.18 \times 10^{2}$ & 14.8 \\
\hline
\end{tabular}

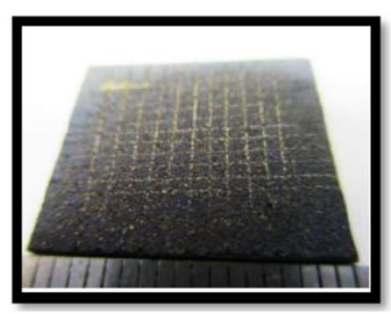

2 cuts perpendicular to each other

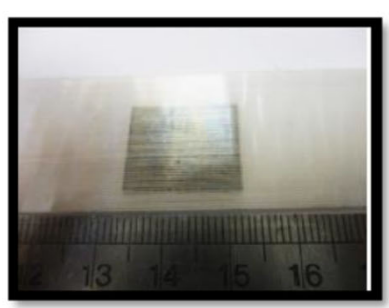

apply the adhesive tape

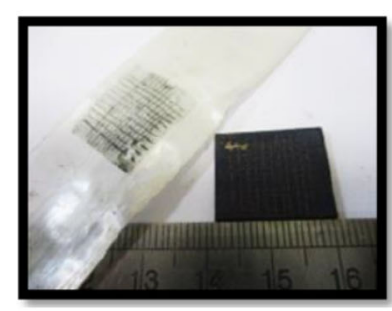

sample after test run

Fig. 5 Analysis of adhesion 


\section{Adhesion test}

Mechanical adhesion is checked by cross cut adhesion. As shown in Fig. 5 the following steps have been performed:

By comparing the result of test with the reference standard ASTMD3359-9 the following result was achieved. According to standard the coating are placed at $4 \mathrm{~B}$, which means that the dug off coating by the cross cut is less than $5 \%$ laced.

\section{Conclusions}

1. Reducing the rate of torch gas prevents the divergence of plasma spraying, excessive speed and lack of nonmelting of the powder particles.

2. The curvature of spraying, resulting in non-uniform coating on the edges, is prevented by removing powder carrier gas.

3. The best range of spraying distance is from 12 to $17 \mathrm{~cm}$.

In addition, it should be noted that with increasing spray distance, spray time should be increased, too.

By reducing the distance in order to prevent oxidation and adhesion reduction, time is limited to $10 \mathrm{~s}$.

Publisher's Note Springer Nature remains neutral with regard to jurisdictional claims in published maps and institutional affiliations.

Open Access This article is distributed under the terms of the Creative Commons Attribution 4.0 International License (http://crea tivecommons.org/licenses/by/4.0/), which permits unrestricted use, distribution, and reproduction in any medium, provided you give appropriate credit to the original author(s) and the source, provide a link to the Creative Commons license, and indicate if changes were made.

\section{References}

1. Suleiman, M.J., Muhammad, S.M., Abdullah, A.N.: Effect of plasma spraying parameters on the microstructure and strength of $\left(\mathrm{TiO}_{2}\right)$. Int. J. Min. Metall. Mech. Eng. 3(4), 193-197 (2015)

2. Feng, L., Xu, D., Lei, A.: Preparation of $\left(\mathrm{TiO}_{2}\right)$ nano powders by plasma spray and characterizations. J. Therm. Spray. Technol. 17(4), 473-477 (2008)

3. Ong, J.L., Carnes, D.L., Bessho, K.: Evaluation of titanium plasma-sprayed and plasma-sprayed hydroxyapatite implants in vivo. Biomaterials 25(19), 4601-4606 (2004)

4. Handzlik, P., Fitzner, K.: Semiconducting properties of anodic oxide films grown on titanium in Ringer and PBS solutions. Metall. Mater. 55(2), 521-532 (2010)

5. Goudarzi, M., Saviz, S., Ghoranneviss, M., Salar, Elahi A.: Equipment antiseptic processes using the atmospheric plasma sprayed copper coatings. J. X-ray Sci. Technol. Med. 25(3), 479-485 (2017)

6. Heiman, R.B.: Plasma Spray Coating Principles and Applications. Wiley, New York (1996). ISBN 3-527-29430-9

7. Davis, J.R.D.: Handbook of Thermal Spray Technology, pp. 41-276. ASM International and the Thermal Spray Society, USA (2004)

8. Roseberry, T.J., Boulger, F.W.: A Plasma Flame Spray Handbook. US Department of Commerce Report MT-043, National Technical Information Service, Springfield (1977)

9. Ryu, J., Choi, W.: Substrate-specific photocatalytic activities of $\left(\mathrm{TiO}_{2}\right)$ and multi-activity test for water treatment application. Environ. Sci. Technol. 42(1), 294-300 (2007)

10. Seifalian, A., Demel, A., Kalaskar, D.M.: Nano Medicine, pp. 111-136. One Central Press, UK (2014)

11. Baboian, R.: Corrosion Tests and Standards Application and Interpretation. Chapter 53-titanium (2004). ISBN 0-8031-2098-2 